\title{
Atomic modifications by synchrotron radiation at the calcite-ethanol interface
}

Pasarín, I. S.; Bovet, Nicolas Emile; Glyvradal, Magni; Nielsen, Martin Meedom; Bohr, Jakob; Feidenhans'l, R.; Stipp, Susan Louise Svane

Published in:

Journal of Synchrotron Radiation

Link to article, DOI:

$10.1107 / S 0909049512021504$

Publication date:

2012

Document Version

Publisher's PDF, also known as Version of record

Link back to DTU Orbit

Citation (APA):

Pasarín, I. S., Bovet, N. E., Glyvradal, M., Nielsen, M. M., Bohr, J., Feidenhans'l, R., \& Stipp, S. L. S. (2012). Atomic modifications by synchrotron radiation at the calcite-ethanol interface. Journal of Synchrotron Radiation, 19(4), 530-535. https://doi.org/10.1107/S0909049512021504

\section{General rights}

Copyright and moral rights for the publications made accessible in the public portal are retained by the authors and/or other copyright owners and it is a condition of accessing publications that users recognise and abide by the legal requirements associated with these rights.

- Users may download and print one copy of any publication from the public portal for the purpose of private study or research.

- You may not further distribute the material or use it for any profit-making activity or commercial gain

- You may freely distribute the URL identifying the publication in the public portal 


\section{Synchrotron \\ Radiation}

Received 13 October 2011

Accepted 11 May 2012
Journal of

ISSN 0909-0495

\section{Atomic modifications by synchrotron radiation at the calcite-ethanol interface}

\author{
I. S. Pasarín, ${ }^{\mathrm{a} *}$ N. Bovet, ${ }^{\mathrm{a}}$ M. Glyvradal, ${ }^{\mathrm{b}}$ M. M. Nielsen, ${ }^{\mathrm{c}}$ J. Bohr, ${ }^{\mathrm{d}}$ \\ R. Feidenhans' $\left.\right|^{\mathbf{b}}$ and S. L. S. Stipp ${ }^{\mathbf{a}}$
}

\begin{abstract}
${ }^{\mathbf{a}}$ Nano-Science Center, Department of Chemistry, University of Copenhagen, Denmark, ${ }^{\mathbf{b}}$ Niels Bohr Institute, University of Copenhagen, Denmark, 'Department of Physics, Technical University of Denmark, Denmark, and d Department of Micro- and Nanotechnology, Technical University of Denmark, Denmark. E-mail: isp@nano.ku.dk
\end{abstract}

\begin{abstract}
This article reports on studies of the chemical alterations induced by synchrotron radiation at the calcite-ethanol interface, a simple model system for interfaces between minerals and more complex organic molecules containing $\mathrm{OH}$ groups. A combination of X-ray reflectivity and X-ray photoelectron spectroscopy of natural calcite, cleaved in distilled ethanol to obtain new clean interfaces, indicated that, during a $5 \mathrm{~h}$ period, the two top atomic layers of calcite, $\mathrm{CaCO}_{3}$, transform into calcium oxide, $\mathrm{CaO}$, by releasing $\mathrm{CO}_{2}$. Also, the occupation of the first ordered layer of ethanol attached to calcite by hydrogen bonds almost doubles. Comparison between radiated and non-radiated areas of the same samples demonstrate that these effects are induced only by radiation and not caused by aging. These observations contribute to establishing a time limit for synchrotron experiments involving fluid-mineral interfaces where the polar $\mathrm{OH}$ group, as present in ethanol, plays a key role in their molecular structure and bonding. Also, the chemical evolution observed in the interface provides new insight into the behavior of some complex organic molecules involved in biomineralization processes.
\end{abstract}

(C) 2012 International Union of Crystallography Printed in Singapore - all rights reserved

\section{Introduction}

Calcite, $\mathrm{CaCO}_{3}$, appears in nature as an inorganic mineral and as a common biomineral. Particularly interesting are the coccolithophorids, a group of algae that produce calcite shields to cover their one cell. These shields, or coccoliths, are interlocking platelets composed of 20 to 60 individual calcite crystals, each with its own crystallographic orientation. It is known that algae use polysaccharides to control the growth of the coccoliths (Marsh, 1994), but it is not known how the cell controls the activity of the complex sugars, or how the different species can engineer such different and elegant designs.

Previous studies of coccolith associated polysaccharide (CAP) activity on calcite (Henriksen et al., 2004; Yang et al., 2008) have established that the $\mathrm{OH}$ groups on the complex sugars play a key role. Further studies investigated $\mathrm{OH}$ behavior of water, H-OH (Bohr et al., 2010; Stipp \& Hochella Jr, 1991; Stipp, 1999) and the simplest organic chain molecule with both a fatty $\mathrm{CH}_{3}$ end and a polar $\mathrm{OH}$ end, ethanol, $\mathrm{CH}_{3} \mathrm{CH}_{2}-\mathrm{OH}$, or Et-OH (Cooke et al., 2010; Sand et al., 2008). Our aim was to further explore the interaction of calcite and $\mathrm{OH}$ using X-ray reflectivity and, in the process, we discovered the limits of time and intensity where the interaction of the
X-ray beam destroys the ordered structure at the interface between the crystalline solid and adsorbed organic molecules.

$\mathrm{X}$-ray reflectivity is excellent for defining the thickness and density of adsorbed layers that are only a few ångströms thick (Bohr et al., 2010; Chiarello et al., 1993; Geissbühler et al., 2004). Recent X-ray reflectivity investigations of the calciteethanol interface have demonstrated that, at room temperature, ethanol bonds to calcite forming a layered structure where $\mathrm{OH}$ attaches through hydrogen bonds on the terminated bulk calcite structure and the fatty $\mathrm{CH}_{3}$ ends point away from the solid (Pasarín et al., 2012). The next ethanol layer orders with the fatty ends facing the first layer, with a gap between the two, as is observed between atomic layers in a crystalline structure. This ordering is disrupted with time by the power of the X-ray beam, as has been observed in other systems (Frydman et al., 1997; Graham et al., 1993; Rieke et al., 1993; Zerulla \& Chassé, 1999). Regarding calcite, there is also evidence that electron beams can induce chemical changes on its surfaces by liberating $\mathrm{CO}_{2}$ from the carbonate groups, thus forming layers of $\mathrm{CaO}$ in the interface (Baer \& Blanchard, 1993). This work presents evidence for these disruptions and offers information about how to find the limits in time and power to avoid beam damage on ionic insulating materials. 


\section{Materials and methods}

\subsection{Samples}

We used single crystals of optical-quality Iceland spar calcite (from Chihuahua, Mexico, purchased from Ward's Scientific, Rochester, NY, USA). X-ray reflectivity requires flat surfaces of at least $5 \mathrm{~mm}$ long and wide. Calcite is a rhombohedral mineral, with three symmetrically identical, perfect cleavage directions. Careful cleavage produces surfaces that are atomically flat over several micrometers, so surface roughness is far below the level needed for detecting monolayers of atoms or low-molecular-weight molecules, such as water and ethanol. The spectral reflectance of calcite is extremely high (Bohr et al., 2010), making its physical properties well suited for studying adsorbed layers with X-ray reflectivity. We cleaved broad thin slices using the method described by Stipp \& Hochella Jr (1991), scoring along the cleavage direction with a scalpel until a fracture formed and propagated through the crystal and the sample fell away. The samples were about $10 \mathrm{~mm}$ long, $8 \mathrm{~mm}$ wide and $1.5 \mathrm{~mm}$ thick. Although calcite $\{10 \overline{1} 4\}$ cleavage terraces are atomically flat, nanometer-scale steps between terraces produce a shadow for the incident or reflected X-ray beam, so a correction for the loss of intensity must be made during data analysis (Pasarín et al., 2012). The correction varies in magnitude depending on how well the fracture follows the cleavage plane.

We cleaved the samples under liquid ethanol to avoid adsorption of water vapor from the air. We used clean tools and avoided touching the surface of the sample with anything, moving it with stainless steel tweezers and touching it only by the sides. The samples remained immersed in ethanol until use to minimize the accumulation of adventitious carbon, the hydrocarbon contamination that comes from the air or solutions and to which calcite is attractive (Stipp \& Hochella Jr, 1991). The ethanol had been distilled to remove impurities (Lund \& Bjerrum, 1931); for example, hydrocarbons from storage in plastic bottles and zinc from the industrial process used to remove water from commercial $100 \%$ ethanol. Our ethanol was $100 \%$ pure, with no water at the beginning of the experiments.

The samples were stored in distilled ethanol inside a closed vessel for a maximum of $6 \mathrm{~h}$ before mounting them in the measuring chamber. This was a kapton cylinder supported by an aluminium frame. The chamber is air tight, allowing control of the atmosphere inside. To minimize contamination and loss of X-ray intensity by scattering in air, we filled the chamber with helium at $1 \mathrm{~atm}$ pressure. To maintain equilibrium ethanol vapor pressure in the atmosphere above the surface, we used a gas-flow system where the helium bubbled through distilled ethanol before entering the measuring chamber.

\subsection{Surface analysis}

$\mathrm{X}$-ray reflectivity $(\mathrm{XR})$ is a standard technique for studying the nanometer-scale profile of interfaces (Cowley \& Ryan, 1987; Fenter \& Sturchio, 2005; Geissbühler et al., 2004). An $\mathrm{X}$-ray beam is shone at a low angle on a flat surface and the intensity of the reflected beam can be measured. The inci- dence angle for successful XR ranges from just below the critical angle, defined as the one below which a material reflects all the beam (for X-rays usually under $1^{\circ}$ ), to where the reflected intensity fades to background or the first diffraction peak appears. The reflected intensity from any material depends on the structure of the interface. If there are several layers of material on the solid, the reflectivity is a combination of internal reflections and refractions in the various layers that form the interface. The parameters that control the reflectivity are layer thickness $(Z)$, density $(\rho)$ and the roughness between each of the layers $(\sigma)$ (Chiarello et al., 1993; Parratt, 1954; Weber \& Lengeler, 1992; Wogelius et al., 1999).

We performed the experiments at beamline BW2 at the synchrotron radiation facility at DESY, Hamburg (Germany). The facility is described elsewhere (Drube et al., 1995, 1998; Schulte-Schrepping et al., 1998). The X-ray energy was $10 \mathrm{keV}$ $(\lambda=1.24 \AA)$ and the flux at the sample was $4 \times 10^{12} \mathrm{~s}^{-1}$. The slits used to control the beam size had a $2 \mathrm{~mm}$ horizontal aperture and $0.2 \mathrm{~mm}$ for the vertical.

X-ray photoelectron spectroscopy (XPS) uses X-rays to probe a surface and collect information about chemical composition and bonding. We further investigated the nature of the changes that an X-ray beam can induce at the calciteethanol interface using a laboratory XPS on the same samples we explored with XR, allowing direct comparison, and with other freshly prepared samples where we could vary the time of the X-ray exposure. We prepared the samples in exactly the same way as for the XR experiments, but we used a shield to protect the sample that was not being exposed. In this way we could compare the areas that were radiated for $8 \mathrm{~h}$ with those that were not radiated, thus ensuring that the extent of X-ray exposure was the only possible cause for differences in the data. For further comparison we also cleaved a calcite sample inside the XPS vacuum chamber and dosed it in the ultrahighvacuum (UHV) chamber with a layer of ethanol at $150 \mathrm{~K}$. We needed the low temperature because, in UHV, ethanol desorbs from calcite (Bovet et al., 2012). We used a Kratos Axis Ultra, with a monochromatic aluminium $K_{\alpha} \mathrm{X}$-ray source $(h v=$ $1486.6 \mathrm{eV}$ ) at a power of $150 \mathrm{~W}$, a pass energy of $10 \mathrm{eV}$ and a step size of $0.1 \mathrm{eV}$ for high-resolution scans. The X-ray beam impact during the XPS analyses did not produce any observable damage to the samples because the XPS beam is much less intense than that of the synchrotron beam. All spectra were analysed with the CasaXPS software and the binding energies were calibrated using the carbonate peak at $290.1 \mathrm{eV}$ (Stipp \& Hochella Jr, 1991).

\section{Results}

\subsection{X-ray reflectivity}

Depending on the sample, it takes from $20 \mathrm{~min}$ to $1 \mathrm{~h}$ to make a proper alignment. This makes it impossible to collect a data set that has not been exposed to radiation. Instead, we collected the first data set just after 35 min of alignment. Looking at the results plotted on Fig. 1, the 35 min set shows a 
different overall slope than the others, because the sample alignment during that data uptake was not optimal. Of course, we corrected it afterwards, starting by the $145 \mathrm{~min}$ set, leaving the rest of the data unaffected. Nevertheless, it did not cause any major disturbance on the resulting density profile, yielding only a slight increase in the overall roughness, without significant changes in the other density profile features, i.e. densities and thicknesses. To collect a data set representative of a non-radiated sample that would be equivalent to a measurement at $t=0$, we moved to a new location $2 \mathrm{~mm}$ to the side of the previous data collection area. Because the beam is $2 \mathrm{~mm}$ wide, we could be sure that moving $2 \mathrm{~mm}$ would result in a site that had previously not been radiated. This allowed us to collect a set of data without re-aligning the sample, thus avoiding beam damage during the process. Therefore, the $500 \mathrm{~min}$ data set is our 0 min measurement. The data in Table 1 show that there was no effect of aging on either the calcite or the ethanol on the 500 min sample, confirming that the changes observed in the other scans was a result of the high-energy X-rays alone.

From previous work we know that in the calcite-ethanol interface the ethanol on top of the calcite is structured in two layers separated by a gap (Fig. 2). The first ethanol layer, EtOH-1, is about $6 \AA$ thick. It consists of ethanol molecules standing up on top of the calcite and attached to it by hydrogen bonds. Then there is a gap about 1 or $2 \AA$ thick, $\mathrm{EtOH}-2$, before the bulk ethanol layer, EtOH-3, that has a thickness of about $14 \AA$. The justifications for this interpretation are given in previous studies (Pasarín et al., 2012).

The position of the reflectivity oscillations for all the data sets remains almost constant (Fig. 1), meaning that the

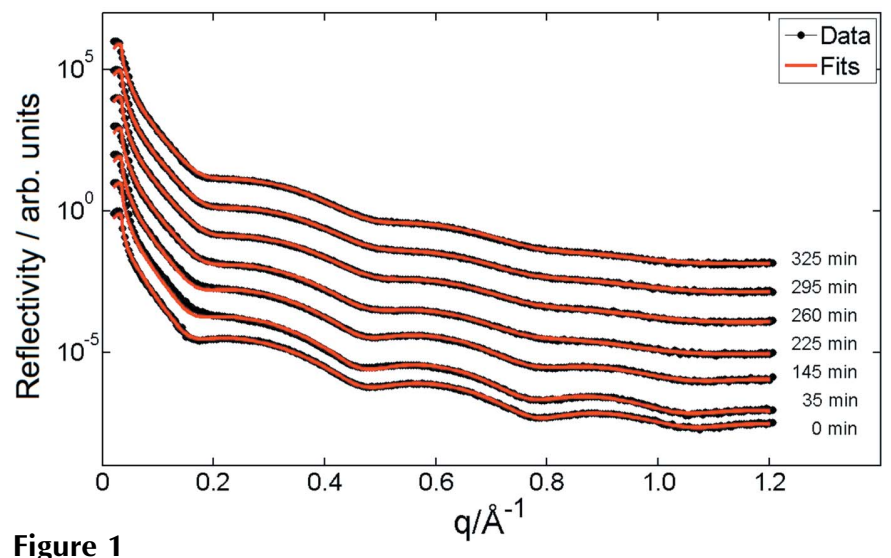

Time evolution and model fits for the reflectivity data. All scans are from the same location except the one from $0 \mathrm{~min}$, which was taken after $500 \mathrm{~min}$ at a new site on the same sample that had not been exposed to the X-ray beam during the initial set of experiments. The sharper features of the scan from a pristine area suggest that loss of detail in the time evolution series results from beam damage, not from any natural aging process at the interface. thickness of the ethanol on the calcite suffers minimal alteration. There is also a flattening of the oscillations with time. The reason for this could be a combination of factors, given the correlations between density $(\rho)$, roughness $(\sigma)$ and thickness $(Z)$ of each layer in the system.

To test the sensitivity of the model for each of the parameters, we made series of models varying one parameter at a time (Fig. 3). An obvious reason for the oscillation-flattening would be an increase of the interface roughness; however, as Fig. 3(a) shows, small deviations from the reference value, $\sigma_{\text {Calcit/Ethanol }}=0.7$, produce almost no change and larger variations do not fit the data. We also observed a similar effect for $\sigma_{\mathrm{EtOH}-3 / \mathrm{He}}$, but over a wider range of values. Checking the influence of the bulk ethanol thickness, $Z_{\mathrm{EtOH}-3}$, we obtained

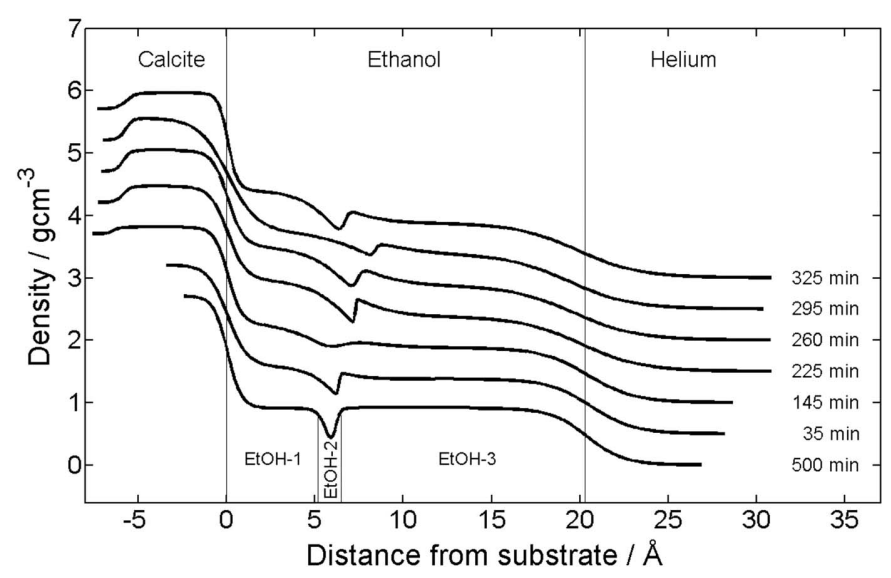

Figure 2

Density profiles derived from the time series in Fig. 1 using the model established by Pasarín et al. (2012). We kept the ethanol layer thickness constant. The gap, labeled EtOH-2, between the ethanol that is hydrogen bonded to the calcite interface, EtOH-1, and the bulk ethanol, EtOH-3, is visible during the time series, but its features are not well resolved. This loss of resolution arises because the last oscillation, from $q=1.0$ to $1.2 \AA^{-1}$, is not distinguishable from the background. However, a clear difference is the increase in the density of the two first molecular layers of calcite $(\sim 6 \AA)$ and in the ethanol attached to them (Table 1). The $y$-axis scale directly matches only the 0 min density profile. The other profiles have been shifted by $0.5 \mathrm{~g} \mathrm{~cm}^{-3}$ each, to allow differences to be seen. 

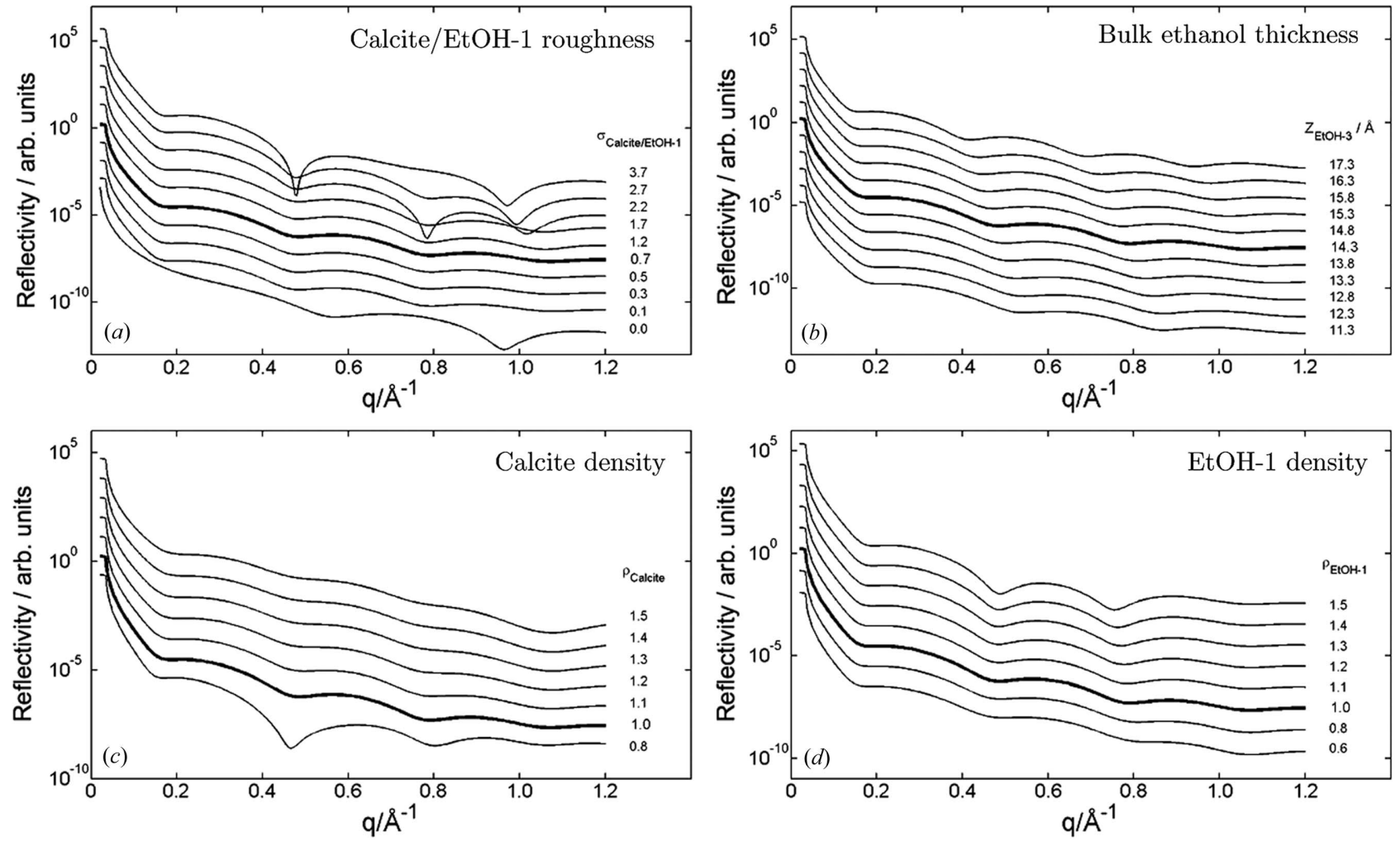

Figure 3

Sensitivity analysis of the model parameters for treating the data of Fig. 1 . Using the 0 min data set as reference, we varied a single parameter at a time: (a) roughness of the interface between the calcite and the first ethanol later, $\sigma_{\mathrm{Calcit} / \mathrm{EtOH}-1} ;(b)$ thickness of the bulk ethanol, $Z_{\mathrm{EtOH}-3} ;(c)$ relative density of the two first molecular layers of calcite, $\rho_{\text {Calcite, }}$, and $(d)$ relative density of the ethanol layer bonded to the calcite, $\rho_{\mathrm{EtOH}-1}$. From this analysis we can interpret that an increase in the density of the two first calcite layers is responsible for the flattening of the oscillations and an increase in the density of the first structured ethanol layer decreases the amplitude of the oscillation at $q=1.0$ to $1.2 \AA^{-1}$. Changes in interface roughness and bulk ethanol thickness (EtOH-3) have a negligible effect.

an increase or decrease in the relative distances between the oscillations, thus confirming that the ethanol thickness has to stay constant (Fig. 3b). Thus, the main reason for the flattening is an increase in the density of the top $\sim 6 \AA$ of calcite, which corresponds to two atomic layers, and the ethanol attached to it, EtOH-1. Fig. 3(c) indicates that an increase in the density of calcite flattens the first three oscillations, while Fig. 3(d) illustrates how the density of the layer EtOH-1 also has to increase to account for the smearing of the last bump.

Using the indications that increases in the densities of the calcite and the first ethanol layer should be the main reason for the time evolution of the reflectivity, we performed the data fitting to obtain the density profiles that Fig. 2 displays. In Table 1 there is a summary of the parameters describing the density profiles. These results show that, as expected from the models, the main change occurring is a density increase of the calcite surface and the ethanol layer attached to it. The density increase in the calcite occurs through a layer of about $6 \AA$, i.e. about the thickness of two calcite atomic layers $(2 \times 3.2 \AA)$. Regarding EtOH-1, apart from its density increase it also shows higher interfacial roughness with the gap separating it from the bulk of liquid ethanol, EtOH-2. The interfacial roughness between the bulk ethanol layer, EtOH-3, and the helium also increases from an initial value of about 2.0 to 3.2. All these changes have already begun by $35 \mathrm{~min}$ and are clearly observable by $145 \mathrm{~min}$. Beyond $225 \mathrm{~min}$ the system becomes stable and we observed no further change.

After $225 \mathrm{~min}$ the density of the two top calcite atomic layers was $3.0 \mathrm{~g} \mathrm{~cm}^{-3}$ instead of the usual $2.71 \mathrm{~g} \mathrm{~cm}^{-3}$, and the density of EtOH-1 increased from its base value of 0.8 to $1.3 \mathrm{~g}$ $\mathrm{cm}^{-3}$. On the other hand, the density of the bulk ethanol, EtOH-3, remained constant at its standard value of $0.8 \mathrm{~g} \mathrm{~cm}^{-3}$ (0.789 $\mathrm{g} \mathrm{cm}^{-3}$ ) (Lide, 1998-1999).

Before collecting the data set at 295 min we opened the kapton chamber. The effects were not obvious from the curves of Fig. 1, but after data analysis the change in the density profile is clear, as shown in Fig. 2. Opening the cell to the atmosphere allowed water vapor to enter the chamber and it took several minutes for the controlled helium atmosphere inside the kapton chamber to remove the remaining water vapor and stabilize the system again. The results from $t=325$ and $t=0 \mathrm{~min}$ (measured after $500 \mathrm{~min}$ on a non-radiated spot of the same sample) show that the effects were not permanent; the flow of helium was enough to purge the system and reestablish stable conditions.

\subsection{X-ray photoelectron spectroscopy}

The XPS data offer extra information about the composition of the calcite-ethanol interface. The spectra of Fig. 4 show 


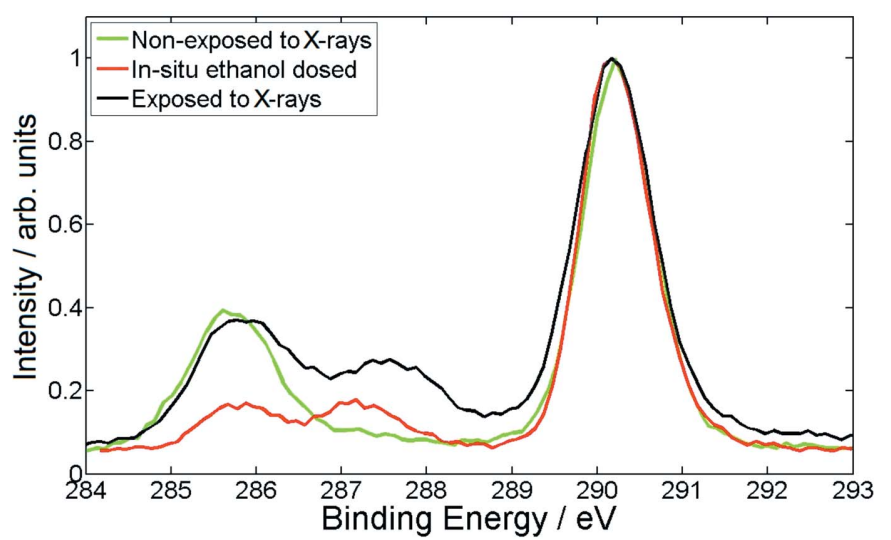

Figure 4

XPS spectra for the $\mathrm{C} 1 s$ region from calcite crystal surfaces treated differently. The red line belongs to the dosed in situ ethanol monolayer, the black to the surface radiated for $8 \mathrm{~h}$ and the green line to the surface non-exposed to $\mathrm{X}$-rays. The peak at $285.5 \mathrm{eV}$ represents the energy of the core electrons from $\mathrm{C}$ involved in $\mathrm{C}-\mathrm{H}$ and $\mathrm{C}-\mathrm{C}$ bonds, indicating the presence of ethanol molecules and also adventitious carbon. The peak at $287.1 \mathrm{eV}$ (red) represents $\mathrm{CH}_{2}-\mathrm{OH}$ bonds from the dosed ethanol and the peak at $287.5 \mathrm{eV}$ (black) is for any $\mathrm{C}-\mathrm{O}($ e.g. $\mathrm{C}-\mathrm{OH}$ or $\mathrm{C}-\mathrm{O}-\mathrm{O})$. The differences in the $\mathrm{C}-\mathrm{O}$ peak from the radiated area (black) compared with the two other spectra indicate that there is more $\mathrm{OH}$ bonding than in a standard calcite-ethanol interface, i.e. from ethanol or ethanol residue, and that it is attached via stronger bonds.

a clear difference for samples that have been radiated (black line) and not radiated (green line). The peak at $290.1 \mathrm{eV}$, corresponding to $1 s$ electrons released from carbon that is bonded within carbonate in calcite, shows an $8 \%$ increase in FWHM on the sample exposed to X-rays, which indicates that, in the radiated area, order has been disrupted slightly by some new chemical environments for the carbonate groups. The peaks that represent core electrons from atoms bound in $\mathrm{C}-$ $\mathrm{H}$ and $\mathrm{C}-\mathrm{C}$ bonds, observed at about $285.5 \mathrm{eV}$, indicate ethanol and/or other hydrocarbons. The energy of this peak remains constant, as expected, because being both areas in the same sample they have the same chances of acquiring adventitious carbon, most likely ethanol residue, on their way from the XR measuring chamber to the XPS vacuum. In contrast, the radiated area shows a peak at about $287.5 \mathrm{eV}$ that is absent in the non-radiated area. This peak comes from $\mathrm{C}-$ $\mathrm{O}$ bonds $($ e.g. $\mathrm{C}-\mathrm{OH}$ or $\mathrm{C}-\mathrm{O}-\mathrm{O})$, that is evidence of a reaction product of ethanol. Even more so, this peak is present in the radiated area but not in the non-radiated area, indicating a change in the nature of the bonding of the ethanol to the calcite, i.e. it has undergone reaction. Hydrogen bonding is not strong enough to prevent ethanol desorption in a vacuum, but the ethanol in the radiated area remains attached, so its bonding with calcite has been changed.

Comparing the spectrum from the radiated area (black line) with the spectrum from the sample dosed in situ with one monolayer of ethanol (red line), we see no difference in the carbonate peak, $290.1 \mathrm{eV}$ (Stipp \& Hochella Jr, 1991), but the other two are different. The intensity at $285.5 \mathrm{eV}$, the $\mathrm{C}-\mathrm{C}$ bonding peak, is smaller for the dosed sample. This is expected, because the cleaving in a vacuum keeps the sample clean from adventitious carbon. What is more relevant is the difference in the intensities for the $\mathrm{C}-\mathrm{O}$ peak, $287.1 \mathrm{eV}$, which is almost double for the radiated area than for the dosed sample. The intensity ratio $I_{\mathrm{CO}} / I_{\mathrm{CO}_{3}}$ is equal to 0.17 for the non-radiated area and 0.31 for the radiated area. Also, in the radiated sample the $\mathrm{C}-\mathrm{O}$ peak shifts to $287.5 \mathrm{eV}$. These two differences indicate that the amount of ethanol, or at least the $\mathrm{C}-\mathrm{O}$ bonding environment, is about double that for fresh ethanol adsorbed on a fresh calcite surface, indicating that the chemical nature of the interface has changed.

Our explanation for these changes is that the X-rays induce a change in the nature of the calcite-ethanol bonding. First, the high energy of the beam provokes the release of $\mathrm{CO}_{2}$ from the carbonate of the calcite, as happens when an electron beam interacts with calcite (Baer \& Blanchard, 1993; Stipp et al., 1992). This creates a layer or two of calcium oxide. The density of $\mathrm{CaO}$ is $3.35 \mathrm{~g} \mathrm{~cm}^{-3}$. The layer is likely to be inhomogeneous, so an average of the densities of $\mathrm{CaO}$ and calcite $\left(2.71 \mathrm{~g} \mathrm{~cm}^{-3}\right)$ is consistent with the value we obtain from the XR for the top calcite layers: $3.0 \mathrm{~g} \mathrm{~cm}^{-3}$ (Table 1). The beam also provokes a shift from the hydrogen bonding of the ethanol with the carbonate groups to a more covalent type of bonding with the $\mathrm{O}$ atoms in the new $\mathrm{CaO}$ layer. The stronger nature of the bond, i.e. that the ethanol has undergone a reaction, explains why, under vacuum, it does not desorb from the radiated area, while the ethanol in the non-radiated surface does. Such covalent bonding could also explain the shift of the peak from $287 \mathrm{eV}$ towards higher binding energy. Compared with a monolayer of ethanol, the FWHM becomes $8 \%$ wider in the exposed sample, reflecting a beam-induced change in the chemical environment of the carbon, likely from $\mathrm{C}-\mathrm{O}$ bonding being replaced by at least some $\mathrm{C}-\mathrm{O}-\mathrm{O}$. To account for the doubling of the intensity in that same peak, one can think that the radiated sample contains two reacted ethanol layers instead of a single ordered layer as for the dosed sample; XR shows no change in thickness of the ethanol layer attached to calcite, further evidence suggesting it has reacted. What XR shows, however, is a higher density layer, $1.3 \mathrm{~g} \mathrm{~cm}^{-3}$, instead of the $0.8 \mathrm{~g} \mathrm{~cm}^{-3}$ usual for ethanol. This is almost double, consistent with the double intensity for the $\mathrm{C}-$ $\mathrm{O}$ peak for the radiated area, suggesting that there is twice as much $\mathrm{OH}$ in the adsorbed layer.

\section{Conclusions and implications}

The XR data indicate that, after $145 \mathrm{~min}$, changes are induced in the calcite-ethanol interface by the power of a synchrotron radiation beam. This allows us to establish an analysis time limit of about $2 \mathrm{~h}$ for a $10 \mathrm{keV}$ beam, with a flux of $4 \times$ $10^{12} \mathrm{~s}^{-1}$, before the integrity of a calcite surface is compromised. Although these results are derived from the behavior of the calcite-ethanol interface, calcite interaction with other organic molecules where hydrogen bonding occurs through hydroxide $\left(\mathrm{OH}^{-}\right)$is likely to be affected in a similar way, such as calcite with other alcohols, polysaccharides, humic and fulvic acids, and so on.

After $225 \mathrm{~min}$ in a $10 \mathrm{keV}$ beam, with a flux of $4 \times 10^{12} \mathrm{~s}^{-1}$, the system stabilizes and the radiation induces no further 
changes. Data suggest that $\mathrm{CO}_{2}$ is removed from about $6 \AA$ into the calcite, the equivalent of two molecular layers. The thickness and density of the adsorbed layer, derived from $\mathrm{X}$-ray reflectivity, and the bonding environments and their relative intensities, derived from X-ray photoelectron spectroscopy, suggest that the power of the synchrotron radiation induces a reaction between the calcite surface and the ethanol while still preserving the layered structure of the interface.

We thank Finn Engström, Henning Osholm Sørensen, Christian S. Pedersen, Klaus Bechgaard and Keld West for challenging questions and discussion, the NanoGeoScience group members for their cheerful willingness to help, the staff from the DESY beamline and Karina Sand for discussion. ISP thanks Christian C. Rein for his help and insight during preliminary experiments and is grateful for the fellowship from the European Commission Marie Curie Early Stage Training Network called MIR (EC-MC-EST-Mineral Interface Reactivity). Research funding was provided by Maersk Oil and Gas A/S and the Danish National Advanced Technology Foundation through the Nano-Chalk Venture.

\section{References}

Baer, D. R. \& Blanchard Jr, D. L. (1993). Appl. Surf. Sci. 72, 295300.

Bohr, J., Stipp, S. L. S., Morris, P. M. \& Wogelius, R. A. (2010). Geochim. Cosmochim. Acta, 74, 5985-5999.

Bovet, N., Yang, M., Javadi, M. \& Stipp, S. L. (2012). J. Phys. Chem. C. Submitted.

Chiarello, R. P., Wogelius, R. A. \& Sturchio, N. C. (1993). Geochim. Cosmochim. Acta, 57, 4103-4110.

Cooke, D. J., Gray, R. J., Sand, K. K., Stipp, S. L. S. \& Elliot, J. (2010). Langmuir, 26, 14520-14529.

Cowley, R. A. \& Ryan, T. W. (1987). J. Phys. D, 20, 61-68.
Drube, W., Grehk, T. M. \& Materlik, R. T. G. (1998). J. Electron Spectrosc. Relat. Phenom. 683, 88-91.

Drube, W., Schulte-Schrepping, H., Schmidt, H.-G., Treusch, R. \& Materlik, G. (1995). Rev. Sci. Instrum. 66, 1668-1670.

Fenter, P. \& Sturchio, N. C. (2005). Prog. Surf. Sci. 77, 171-258.

Frydman, E., Cohen, H., Maoz, R. \& Sagiv, J. (1997). Langmuir, 13, 5089-5106.

Geissbühler, P., Fenter, P., DiMasi, E., Srajer, G., Sorensen, L. B. \& Sturchio, N. C. (2004). Surf. Sci. 573, 191-203.

Graham, R. L., Baht, C. D., Biebuyck, H. A., Laibinis, P. E. \& Whitesides, G. M. (1993). J. Phys. Chem. 97, 9456-9464.

Henriksen, K., Young, J. R., Bown, P. R. \& Stipp, S. L. S. (2004). Palaeontology, 43, 725-743.

Lide, D. R. (1998-1999). Handbook of Chemistry and Physics. Boca Raton: CRC Press.

Lund, H. \& Bjerrum, J. (1931). Ber. Deutsch. Chem. Ges. 64, 210-213.

Marsh, M. E. (1994). Protoplasma, 177, 108-122.

Parratt, L. G. (1954). Phys. Rev. 95, 359-369.

Pasarín, I. S., Yang, M., Bovet, N., Glyvradal, M., Meedom, M. M., Bohr, J., Feidenhans'l, R. \& Stipp, S. L. S. (2012). Langmuir, 28, 2545-2550.

Rieke, P. C., Baer, O. R., Fryxell, G. E., Engelhard, M. H. \& Porter, M. S. (1993). J. Vac. Sci. Technol. A, 11, 2292-2297.

Sand, K. K., Stipp, S. L. S., Hassenkam, T., Yang, M., Cooke, D. \& Makovicky, E. (2008). Mineral. Mag. 72, 353-357.

Schulte-Schrepping, H., Heuer, J. \& Hukelmann, B. (1998). J. Synchrotron Rad. 5, 682-684.

Stipp, S. L. S. (1999). Geochim. Cosmochim. Acta, 63, 3121-3131.

Stipp, S. L. \& Hochella Jr, M. F. (1991). Geochim. Cosmochim. Acta, 55, 1723-1736.

Stipp, S. L. S., Hochella Jr, M. F., Parks, G. A. \& Leckie, J. O. (1992). Geochim. Cosmochim. Acta, 56, 1941-1951.

Weber, W. \& Lengeler, B. (1992). Phys. Rev. B, 46, 7953-7956.

Wogelius, R. A., Farquhar, M. L., Fraser, D. G. \& Tang, C. C. (1999). In Growth, Dissolution and Pattern Formation in Geosystems. Dordrect: Kluwer.

Yang, M., Stipp, S. L. S. \& Harding, J. H. (2008). Cryst. Growth Des. 8, 4066-4074.

Zerulla, D. \& Chassé, T. (1999). Langmuir, 15, 5285-5294. 